\title{
Teologia e outras linguagens: a contribuição da Teoria da História para o campo do saber teológico
}

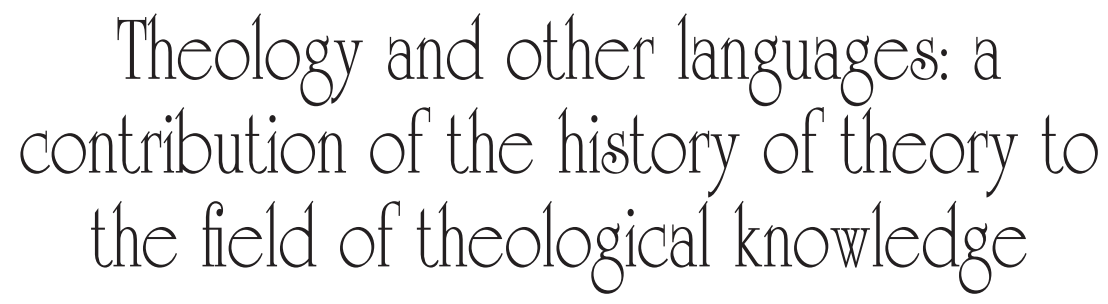

Paulo Augusto Tamanini*

Resumo: A história do cristianismo, para além de abarcar relatos e registros das experiências pretéritas das diversas comunidades de fé e das instituições delas derivadas, serve também como substrato para reflexão teórica interessada em discutir a natureza e o significado da ciência teológica. Afinal, a atuação, missão e evangelização das diversas Igrejas cristãs como instituições são explicadas por uma documentação, por narrativas escritas que foram meticulosamente estudadas em sua historicidade. Ainda que a mensagem cristã seja concebida como realidade sempre atual, estão no passado suas raízes, os indícios e os condicionantes de seu surgimento. Assim, graças ao cuidado das fontes e às análises desenvolvidas pelos pesquisadores, o conhecimento teológico passou de mera formalização de crenças a um saber estrutural capaz qualificar a Teologia como ciência, fundada, então, em bases sólidas do conhecimento acadêmico. Esta comunicação tem como objetivo relacionar algumas teorias e linguagens que cercam o campo historiográfico com a realidade do saber específico da Teologia, averiguando suas aproximações e especificidades. Cumpre reconhecer ao final do artigo, por exemplo, que a História não só complementa a reflexão teológica, mas também

* Doutor em História pela Universidade Federal de Santa Catarina Do Programa de Pós-Graduação em História da Universidade Federal do Paraná. E-mail: tamanini@terra.com.br 
se coloca, através de seu corpo teórico, como um imperativo lógico desta última, uma vez que, sem a hermenêutica sobre as fontes e desprovida da prática de investigação e escrita históricas, a Teologia perderia muito de sua cientificidade.

Palavras-chave: Campo historiográfico e Teologia; fontes e teoria; linguagem teológica.

Abstract: The history of Christianity, as well as cover stories and records of past experiences of the various faith communities and institutions derived from them, also serves as a substrate for theoretical reflection interested in discussing the nature and meaning of theological science. After all, the role, mission and evangelization of the various Christian Churches as institutions are explained by documentation, by written narratives that have been meticulously studied in its historicity. While the Christian message is conceived as ever present reality, its roots are in the past, the evidence and the conditions of its emergence. Thus, thanks to the care of the sources and analyzes developed by the researchers, the theological knowledge went from mere formalization of beliefs to a knowledge structure can qualify theology as a science, founded then on a solid foundation of academic knowledge. This paper aims to relate theories and languages that surround the historiographical field with the reality of specific knowledge of theology, checking their similarities and differences. It should be recognized at the end of the article, for example, that history not only complements the theological reflection, but also stands as a logical imperative of the latter, since without the past sources and devoid of the practice of historical research and writing, theology would lose much of its scientific.

Keywords: historiographical field and theology; sources and theory; theological language 


\section{0 texto teológico no olhar do historiador.}

A salvação trazida por Jesus Cristo persiste na história e, por isso, é uma salvação em continium ${ }^{1}$ que deixa suas marcas pelo tempo. Ainda que o caráter histórico das narrativas acerca do cristianismo tenha sido substituído por outros preocupações, vê-se hoje a necessidade de a teologia incidir eficazmente na história. Até porque a história da salvação não é uma história ao lado da história da humanidade, mas transcorre na história e faz parte dela. Se a História concebe que os fatos estão encadeados numa trama que explicam a ação, pensamento, ideias, subjetividades dos homens no tempo, ${ }^{2}$ a Teologia, por sua vez, acresce a isso, ou seja, a essa ausência de descontinuidade e rupturas nos acontecimentos, a ação de Deus na história.

É provado que a ação de Deus na história humana é um acontecimento registrado, mensurável e que deixou provas documentais. ${ }^{3} \mathrm{O}$ fato de Deus ter entrado na história humana, através da Revelação, Encarnação do Verbo, tornou-se história de salvação numa significativa sucessão de fatos em que atos, gestos, palavras, silêncios se explicam por uma lógica e itinerário de promessa.

Se na pessoa de Jesus Cristo a própria história tornou-se um episódio mensurável e registrado, tal acontecimento não ficou imune de receber uma dimensão que extrapola a própria historicidade do fato. Do ponto de análise da História, a vida de Jesus, apesar das excepcionalidades dos milagres, não fugiu muito da normalidade de outros homens. O que faz dele uma personagem possuidora de historicidade e, por causa disso, fonte de documentação para produção historiográfica e teológica, é a especificidade de sua missão: Ele pode ser visto como o Messias, o Libertador, o Cristo, o Salvador. De toda forma, em Jesus a ação de Deus faz da história uma teofania posta em atos humanos historicamente condicionada, relatada nos Evangelhos. ${ }^{4}$

\footnotetext{
1 DI FALC, Jean-Michel; RADCLIFFE, Timothy; RICCARDI, Andrea. Le Livre noir de la condition des chrétiens dans le monde. Paris: XO Editions, 2014.

2 LE GOFF, Jacques. História e Memória. Campinas, SP: UNICAMP, 2003.

3 CHENU, Bruno. Teologie cristiane dei terzi mondi. Roma: Queriniana, 1988.

4 FILORAMO, Giovanni; BETTIOLO, Paolo. Il Dio mortale. Teologie politiche tra antico e contemporaneo. Brescia: Morcelliana, 2012.
} 
Partindo da afirmação que os escritos dos Evangelhos são uma narrativa, - por isso uma representação de um passado que se vale de fontes documentais para sua estruturação e enunciados - o pesquisador faz uso das ponderações teóricas e metodológicas quando do emprego de fontes históricas na pesquisa teológica. Uma das vertentes da história que tem recebido grande atenção no momento atual é aquela que se debruça sobre os diversos tipos de textos para pensar a escrita, a linguagem e a leitura de um fato. ${ }^{5}$

Não é novidade nem para a Teologia nem para a História que aos mecanismos de produção de todo e qualquer texto orbitam as intencionalidades, a dimensão estética, a intertextualidade e o fim que, na atual corrente investigativa, não são obliterados quando da análise da fonte. Logo para ambos os campos de conhecimento, o texto precisa ser contextualizado, causar estranhamentos, desconcertos, suscitar perguntas, incomodar, cutucar, fugir da acomodação racional, do pedantismo de respostas prontas e ligeiras. Para a Teologia e para a História, a fonte precisa ser dramatizada e desviar-se da arrumação conveniente que faz apenas sossegar, por um tempo, o sempre inquietante insight criador da pessoa humana.

Por isso, contextualizar o texto com o qual se trabalha é indispensável para elucidar o lugar e o tempo em que foi produzido, seu estilo, sua linguagem, o ambiente que envolve o escritor e sua produção. De tal maneira, as noções de leitura, linguagem, apropriação, intertextualidade, dialogismo, são importantes para identificar o modo como em diferentes lugares e momentos uma determinada realidade é pensada e dada a se ler.

\section{As perguntas, as respostas da História e a Teologia}

Os ensinamentos dos Santos Padres gregos insistem que os Evangelhos, e por extensão, toda a Bíblia, não são um amontoamento de escritos sui generis, mas, constituim-se a história da relação de Deus com uma comunidade de fé. Logo, entendem as Escrituras como um

5 KNITTER, Paul F. Introduzione alle Teologie delle Religioni. Roma: Queriniana, 2012. 
elemento essencial da Tradição, que dão à Teologia os pressupostos necessários para se compreender o Sagrado como ciência acadêmica cujo objetode pesquisa e elucidação giram em torno da possibilidade de se pensar 'Deus'. ${ }^{6}$

Contudo, as problemáticas levantadas pelas escolas Teológicas, em suas diversas áreas de conhecimento, ao zelar por seu oficio de ensinar, decodificam os saberes a partir de num lugar e marco temporal distintos. Por isso, é dentro de uma contextualização sócio cultural que o conteúdo acerca de Deus e os assuntos correlatos a ele são estudados e interpretados à luz de um método. Isto posto, é possível inferir que os saberes teológicos são desdobramentos de uma acertada hermenêutica conceitual frente à uma determinada realidade resultante de perguntas, inquietações.

No vasto mundo dos saberes e da produção de conhecimento, as generalizações conceituais por vezes explicam, mas podem também embaralhar e confundir a compreensão dos enunciados. E isso por vezes, acontece quando falamos das diversas escolas Teológicas, sem qualquer critério elucidativo. Ainda que as várias ciências compartilhem os mesmos saberes, sempre haverá uma área de interesse específico. A antropologia olhará para um objeto, respaldada em suas lógicas e métodos; de igual forma a História assim o faz, como também a Teologia. Contudo a Teologia tem um agravante: além da lógica e método levará em consideração a fé. ${ }^{7}$ Ainda que haja compartilhamento e a possibilidade de se beber das mesmas fontes, cada área de conhecimento enxergará seu objeto com as lentes de um método, de uma teoria e que buscarão respostas às perguntas feitas dentro de um panorama conceitual. Mais importante talvez que achar as respostas é saber fazer as perguntas obedecendo a lógica de uma inquietação circunscrita.

Logo, quando dizemos "Teologia” queremos contemplar e se referir à multiforme realidade do conhecimento teológico cristão que explicam e legitimam as ações relacionais do homem e da mulher com

6 CHENU, Bruno. Teologie cristiane dei terzi mondi. Roma: Queriniana, 1988.

7 SANTOS, Hugo N. (Org.). Dimensiones del Cuidado y Asesoramiento Pastoral. Buenos Aires: Ediciones Kairós, 2006. 
Deus, sob a Luz do Evangelho. Neste vasto campo de conhecimento, as vozes de tantos cristãos que se somam a tantas outras de crenças diversas,interrogama prática da Palavra de Deus, dos dogmas, etc em sua hermenêutica, ao mesmo tempo em que procuram um espaço de legitimação. As vozes dos empobrecidos, tão caras à América Latina, as vozes dosimigrantes, que tem atenção redobrada dos bispos da América do Norte e da Europa, as vozes das mulheres que ganham cada vez mais espaço e conseguem chegar aos ouvidos dos teólogos de tantos lugares do globo refletem como o pensar teológico é também tributário dos apelos da contemporaneidade. Percebe-se, então, que o tempo cronológico é objeto de reflexão dentro do campo teológico, assim como é no da História.

Assim, é preciso entender que os plurais saberes que caracterizam diversas escolas teológicas querem responder às questões levantadas com seu efeito prático e decifratório, dentro de um marco temporal e ambiente sociocultural próprios.

Como na História, cabe também à Teologia revisar ou reconsiderar conceitos, usar de linguagens coetâneas e reinterpretar as fontes à luz das demandas de atuais contextos, tendo o cuidado, no entanto, de não cair no casuísmo ou modismos. Então, é preciso pontuar que a Teologia, como outras áreas do saber, ainda que não esteja cega às realidades de cada tempo, não é de toda instável, uma área de saber cambaleante em seus fundamentos, e que se deixa seduzir facilmente por apelos da hora ou pelas inconstâncias de épocas. Tenta, outrossim, acalentar as inquietações, sem perder seu prumo. O olhar que teologiza sobre os diversos temas deve enriquecer o próprio campo de conhecimento, uma vez que, é através das questões levantadas no tempo presente que se mostram e traduzem o entendimento da fé, a forma como é lida a Revelação e ação de Deus no contexto de tempo e lugar.

Assim, as diversas linguagens teológicas que surgem, tendem a estar dentro de uma lógica e coerência respaldada em pressupostos específicos advindos do local e época em que próprio Evangelho é anunciado. Contudo, as discussões, os métodos de estudo e pesquisa, as perguntas levantadas acerca dos objetos devem sempre estar girando em torno da natureza e especificidade da Teologia, sem que haja 
riscos de perda de sua identidade. Ainda que surjam temas e assuntos prementes, a Teologia deve responder às questões atuais tendo como referência a natureza de sua missão. 0 que a Teologia pode responder só caberá a ela fazer, já que ela se assenhora em sua especialidade. Se outras áreas do conhecimento responderem às perguntas que caberia à Teologia elucidar, ainda que seja uma resposta sem legitimação teológica, pode repercutir e trazer comprometimentos a sua própria especificidade. Quando a História ou a Filosofia ou a Antropologia se arvora responder questões fundamentalmente teológicas, denotará um olhar alheio e uma hermenêutica outsiders ao campo próprio do saber específico do que se propõe a Teologia. Tais incursões epistêmicas podem ser lidas como contribuições à disciplina e serem aproveitadas, ou serem catalogadas como invasões e, consequentemente, ignoradas, rechaçadas, pulverizadas. No caso da primeira, enriqueceria o saber teológico porque poderia alargar seus horizontes; na segunda, o campo do saber teológico chancelaria a arrogância de quem se acredita expert daquela área de conhecimento.

\section{Tempo e o lugar: onde se situam os objetos na História e na Teologia?}

Todo e qualquer objeto de estudo ou de pesquisa tem um endereço, uma referência espacial por onde é facilmente localizável. Logo, interpretar o tempo e o lugar dos objetos em estudo, à luz da Teologia ou da História implica a adoção de métodos que possam decifrar códigos que compuseram esse objeto no decorrer de uma cronologia e de um lugar muito bem situado. 0 estudo do tempo e do espaço em relação a qualquer objeto de pesquisa tende, dessa forma, a ser um mergulho valioso e de interpretação poliédrica sobre os acontecimentos passados e que voltam de outra maneira no presente obedecendo à lógica da continuidade ou da ruptura, conforme a conveniência circunstanciada das áreas de pesquisa e de ensino.

Quer material ou não, todo objeto de pesquisa está circunscrito a um lugar, onde é possível flagrar os descaminhos ou trajetos nem sempre lineares das relações entre ele e pessoas, cenários, dando a possibilidade de se descobrir conexões possíveis entre o objeto 
investigado com o espaço onde é encontrado.Se o lugar torna possível a pesquisa, é porque delimita o campo de investigação, as possibilidades de interpretação e as problemáticas levantadas; assim mais que porção geográfica localizada, o lugar em que o objeto está situado institui-se espaço de possibilidades investigativas.

Michel de Certeau certifica que todo lugar tem suas especificidades construídas pela deambulação dos viventes e circunstancias. ${ }^{8}$ E sem os lugares os objetos seriam parcialmente analisados, porque no espaço pulsam as circunstancias, acontecem as contradições, as rupturas e as continuidades. Logo, o termo lugar, ocupa um ponto chave na análise de toda investigação. Decorre disso que não importa saber o nome geográfico em que fatos se sucederam, mas perscrutar o local do acontecimento para melhor compreender o que deles se falam e qual grau de importância que lhes é atribuído nas narrativas.

Isso posto, o lugar em toda pesquisa teológica, ultrapassa a natureza do mero dado e entroniza-se como um elemento importante de idealização e de localização de um problema ou objeto de investigação que não mais perambula desprovido de qualquer endereço. Atento a essa peculiar observação, pode-se com mais largueza compreender os cenários descritos nas narrativas teológicas, dentro de um maior contexto de eventos lhes outorgando outros atributos para além de referência de algo pontualmente situado, espraiando-se à dimensão simbólica onde o acontecido se aninha.

Logo, a narrativa teológica embalada pelo tempo chega a um determinado lugar para lá encontrar concretude, ganhar não somente uma moldura epidérmica, mas carne, sopro de vida, forma e expressão. O espaço, então, mais que mero cenário de cada acontecer histórico, edificado no desdobrar do tempo, foi e é parte essencial de um enredo que sedeixa invadir pelos olhos do pesquisador que, em cada canto, esquina, procura seus protagonistas. É possível afirmar que a narrativa que não encontra prova em uma materialidade espacial, curva-se em si mesma e se apaga. De outro modo, todo e qualquer lugar que não encontre um nexo constitutivo com uma narrativa perde muito

8 CERTEAU, Michel de. A invenção do cotidiano. Artes de fazer. 13 ed. Petrópolis: Editora Vozes, 2007. 
Ano XXIIl • № $86 \cdot$ Jul/Dez 2015

de seu sentido, desbotando as marcas que o tempo nele pincelou. Parece importante que o objeto de análise na Teologia deva também ser percebido igualmente em suas relações espaciais nas quais tudo se conecta.

Santo Agostinho informava que o tempo está ligado à memória e que o homem tem a capacidade de conservar lembranças do passado já que no passado as coisas já não existem, existindo apenas na alma a memória das coisas passadas. ${ }^{9}$ Assim, na História ou na Teologia, quando se pensa o tempo, fala-se da impressão ou da percepção que os fatos poderiam ter causado em pessoas, em um grupo ou uma comunidade. Parece que o pensamento de Agostinho, partindo de conceitos objetivos, aclarou a realidade subjetiva acercado do termo, oportunizando enxergar no presente as coisas passadas. No 'tempo' de Agostinho, nós cristãos reatualizamos memórias em narrativas sempre avivadas por um desejo de fazer reviver o pretérito de Jesus. Tem-se a impressão que ao se escutar uma narrativa do Evangelho, por exemplo, em uma celebração religiosa a mensagem é dirigida a cada um dos presentes. No momento da escuta, o tempo da narrativa é decifrado como coetâneo, próximo.

Tal assentimento vem ao encontro do que afirma Henri Bergson: a existência de dois tempos. ${ }^{10} \mathrm{O}$ tempo dos físicos e matemáticos é, segundo o autor, aquele esquemático e espacial, por isso fugidio: é o momento do acontecimento ou da narrativa. Contudo, há o tempo real movido pela sucessão, mudança, continuidade, memória e pela criação. Esse é o tempo que tem a capacidade de modificar, de alterar e de criar situações. Verifica-se que este é o tempo da escuta da narrativa, capaz de obstruir barreiras, pular séculos e fazer parecer que a mensagem ainda carrega o calor da boca de quem a proferiu.

É o tempo que se deixa descobrir em sua duração pela perspectiva da subjetividade. O tempo da escuta das narrativas do Evangelho, por exemplo, não é o mensurável; é aquele que encontra acolhimento e tem relação com a memória. A História percebe a memória

9 AGOSTINHO. Confissões. Lisboa: Apostolado da Imprensa, 1990.

${ }^{10}$ BERGSON, Henri. Matéria e Memória: Ensaio sobre a relação do corpo com o espírito. São Paulo: Martins Fontes, 1999. 
como instrumento que permite estabelecer uma relação entre o que aconteceu com o momento presente, religando dois instantes um ao outro. A duração de cada acontecimento está relacionada ao grau de interesse que a memória estabelece com as correlações da vida do presente. Assim, a duração do tempo em uma narrativa, bem mais que um processo natural e pragmático de conhecimento das coisas, expressa a forma de se posicionar frente a uma mensagem. Tanto na História quanto na Teologia, busca-se no passado a inteligibilidade das narrativas proferidas e, no presente, a forma e maneiras de sua absorção.Quanto mais presos se estiver aos detalhes do que é narrado, mais perene a mensagem se torna no presente, até porque, o presente dura enquanto a vida permanece, mesmo que ela seja aquela proferida em um longínquo passado e que sempre é reavivada no tempo de cada pregação e em um determinado lugar (igrejas, templos, capelas, casas etc)

Percebe-se então que o tempo e o lugar em que toda e qualquer narrativa é feita institui-se peça-chave para se compreender o porquê de a imagem do passado tornar-se referência de identificações e geradora de novos sentidos. Desta feita, os lampejos imaginativos de lugares, pessoas, circunstancias de que falam da Boa Nova são cenários em que teatralizam os relatos. Consequentemente, prestam-se tanto na História quanto na Teologia a um processo de interpretação dadivoso aberto às curiosidades acadêmicas e que merecem outras abordagens.

É possível afirmar também que a narrativa que não encontra prova na materialidade espacial de igrejas, templos, capelas, casas etc, curva-se em si mesma e se apaga. Assim, todo e qualquer lugar que não encontre um nexo constitutivo com a narrativa perde muito de seu sentido.

Ainda que o conceito de 'tempo' seja mais usual na Filosofia e História, é importante situá-lo em outras áreas das Ciências Humanas, como a Teologia, uma vez que este conceito auxilia a desenvolver o problema da escrita e da narrativa teológica. Para a saudável Teologia, em cada tempo e espaço deverá haver a renovação temática, a multiplicidade metodologia aplicada aos problemas e a variedade de possibilidades analíticas sobreum mesmo tema. 


\section{As Fontes, a Teologia e a História}

A Teologia não está atenta somente as demandas do presente. ${ }^{11}$ Ela, como ciência, necessita olhar igualmente para trás, buscando no passado os fundamentos e as fontes do seu conhecimento.O olhar retrospectivo da Teologia sobre seus fundamentos e fontes lhe possibilita trabalhar interdisciplinarmente com a História, quando pode servir-se, por exemplo, dos conceitos da historiografia no trato e cuidado dos indícios e vestígios deixados pelas pessoas, instituições, documentos textuais. O mesmo serve para quaisquer outros registros que possam fornecer um testemunho ou um discurso proveniente dos acontecimentos. Se ela deve ter um olhar retrospectivo, não se exime de se abrir à interdisciplinaridade para melhor elucidar as questões levantadas, e de ser confluente com outras áreas do saber.

Assim, se estão no passado a preciosas fontes de conhecimento da Teologia, com o auxílio da História, podem igualmente servir de substratos para a tessitura de uma hermenêutica que por si apontam caminhos criativos para a interpretação de nossa fé nos diferentes campos de nossa cultura. Com o intercurso da História, os pesquisadores e teólogos podem se servir de seus métodos para adotar outras perspectivas, dispor de novos métodos no trato com as fontes e observá-las como discursos a serem analisados ou redes de práticas e representações a serem compreendidas em um contexto da ação de Deus na História humana.

A confluência com a História, por exemplo, oportuniza a Teologia a se utilizar do método da taxonomia que capacita uma determinada ciência a fazer uma organização, aparelhamento, catalogação e releitura das fontes de pesquisa e, por derivação,dos atos diagnosticados no ontem. A taxonomia é um método de classificação historiográfica que leva a entender melhor o vasto e complexo universo que constitui o conjunto de todas as fontes históricas possíveis - o que, rigorosamente, coincide com toda a produção material e imaterial humana que

${ }^{11}$ LEVALOIS, Christophe. Prendre soin de l'autre. Une vision chrétienne de la communication.Paris: CERF, 2012. 
pode permitir aos historiadores interagirem com as várias sociedades localizadas no tempo.

O método taxonômico insta a Teologia a constantemente fazer algumas perguntas fundamentais às suas fontes, aproximando-as do objeto cercando-o com questões para melhor compreendê-lo. Como na História, as fontes do saber teológico não estão mortas, finalizadas, engessadas, cristalizadas; também se caracterizam pela dinamicidade do existir.

Porque foram criadas, geradas ou distinguidas, pesam sobre as fontes as condições de sua feitura: ideologias, intencionalidades, derivações, posicionamentos, subjetividades. Desde modo, as questões que incidem sobre elas, quando relacionadas e arguidas lhe dão sobrevidas, novos fôlegos e respiros que levam a produzir conhecimento teológico intermitente, deixando cada vez mais de lado a mera reprodução, repetição, cópia que, consequentemente, aleija a possibilidade de criação e inspiração acerca de seu objeto.

Como se pode inferir da precedente análise acerca do tempo e das fontes, as perspectivas diretoras da interpretação da História e da Teologia portam uma natureza dúplice. A objetividade e a subjetividade mobilizam-se para interpretar a experiência do passado, seja ela de cunho religioso ou não.

Quando observa-se a organização das fontes no tempo intui-se que houve uma intervenção humana nos registros do passado que, anteriormente estava desvinculado de um determinado propósito. Para que seja possível conhecer algum fato passado, faz parte do ofício do historiador ir à busca de outros vestígios para comparar, mensurar, cotejar, chegar os dados. ${ }^{12}$

Sob tal aspecto, nota-se que também a Teologia contemporânea se preocupa com este método de investigação, e se calça para não cair na acusação de edificar um relato tendencioso, e reproduzir suposições e julgamentos que fogem do compromisso da veracidade ou plausibilidade de pesquisa histórica. Logo, as fontes históricas para a Teologia

${ }^{12}$ BURUCÚA, José Emilio (Org.). Historia de las imágenes e historia de las ideas. La escuela de Aby Warburg. Buenos Aires: Centro Editor de América Latina, 1992. 
aparecem como elementos fundantes na edificação do arcabouço de conhecimento teológico equiparado ao da própria Historiografia.

Durante muito tempo, os historiadores acreditavam que o passado não poderia ser reconhecido para fora das fontes escritas oficiais. Tal critério, que perdurou até o século XIX, chegou a determinar que o tempo em que a escrita não fora dominada o passado não poderia ser narrado com veracidade e fundamentos lógicos. Contudo, as tendências historiográficas da Escola dos Annales, da História Social inglesa e da Nova História Cultural do século XX influenciaram a produção historiográfica se baseando em formas diversificadas de fontes. Essa renovação colocou em evidência novos temas, novos objetos e novos métodos promovendo uma verdadeira revolução na escrita da História, e, consequentemente, do ensino de História.

A partir de então, fontes de natureza, visual, oral e sonora foram incorporadas ao conjunto de compreensão do passado. Da mesma forma, no campo teológico, as imagens, os discursos gravados, as cerimônias captados em áudio e vídeo, a pintura e iconografia não são apenas observadas como meios de comunicação, espetacularização, disseminação e meios de evangelização, como servem , a propósito, de registros e fontes documentais. Por exemplo, ao narrar o Concílio Vaticano II, os historiadores e teólogos podem fazer uso das fotografias, dos depoimentos, dos vídeos etc para comporem e recomporem suas narrativas.

\section{Uma contribuição da História para a Teologia da Imagem: 0 uso de fontes imagéticas na construção de um saber teológico}

A imagem possui um registro abrangente, baseado em um dos sentidos que caracterizam a condição humana. ${ }^{13}$ Se a escrita surgiu a partir de um domínio especializado, a leitura e interpretação de imagens sempre acompanharam o saber humano, desde o aparecimento do homem racional, porque a visão vem antes das palavras.

\footnotetext{
${ }^{13}$ KNAUSS, Paulo (Org.) ; Calainho, Daniela Buono (Org.) . Usos do Passado - XII Encontro Regional de História. Rio de Janeiro: Anpuh-Rio, 2006.
} 
O uso das imagens na Teologia enseja orientar os pesquisadores na perspectiva do aprimoramento continuado na qualificação da formação acadêmica, levando em consideração a forte carga simbólica das imagens. A utilização das imagens no campo do saber teológico não é nenhuma novidade: Jesus Cristo utilizava-se de recursos visuais para ensinar e pregar a Boa Nova. Também, em nosso tempo, o ensinamento das primeiras lições de catequese para as crianças se deu pelo uso das imagens. ${ }^{14}$ As paredes das Igrejas, no Oriente, por exemplo estão eivadas de pinturas, ícones, sendo eles os primeiros evangelizadorespara o povo simples, que por muito temponão sabia decifrar os escritos. Lia os evangelhos através das imagens. Também em algumas Dioceses europeias já se implantou, dentro da Pastoral da Cultura, o campo de estudo chamado 'teologia visual' que trata da apreciação da arte sacra, em seus diversos segmentos.

Esta pastoral é um campo especialmente vocacionado para o anúncio e o diálogo não só ad intra mas também na fronteira aberta entre diferentes horizontes de evangelização. A familiaridade das imagens no campo da Teologia não a exime, no entanto, de aprofundar e dialogar com conceitos e metodologias de outras áreas do saber uma vez que o prestígio público ou notoriedade mediática da realidade pictórica possa reverter em favor da presença e disseminação do Evangelho.

Como já exposto, a pertinência de certos temas ou problemas inerentes aos assuntos do sagrado tem aproximado saberes e evidenciado fontes importantes, antes relegadas ao esquecimento. Com isso, a História e as ciências teológicas abrem-se ao debate epistemológico inaugurado diversificação de fontes, ${ }^{15}$ interpretando os 'textos', os 'acontecimentos' e as 'imagens' (religiosas ou não) focando suas análises no pensamento, percepção e ações do indivíduo, rompendo com o modo positivista e tradicional de se construir suas narrativas. Percebe-se também - em um contexto de um mundo cada vez mais informatizado - que os campos do saber historiográfico e teológicotêm

${ }^{14}$ FABRIS, A. Redefinindo o conceito de imagem. Revista Brasileira de História. São Paulo, v.18, n.35, p. 217-224, 1998

${ }^{15}$ LEITE, Miriam Lifchitz Moreira. Texto visual e texto verbal. Revista Catarinense de História, n. 5, p. 67-85. 
um encontro marcado também com as fontes visuais e que estas traduzem-se em objetividade do conhecimento e dados científicos, passíveis de interpretação. Logo, a imagem é um objeto de campo multidisciplinar singular dentro dos diversos campos do saber e que, no Brasil, passou a partir de 1990, a ganhar terreno como fonte documental para a pesquisa acadêmica.

O reconhecimento de novas possibilidades de estudo sobre o uso da imagem na História e na Teologia coloca a visualidade ou a centralidade do olhar no cerne das interrogações e problemáticas das atuais pesquisas. Logo, é possível fazer pesquisas de História e de Teologiautilizando-se de imagens desde que estas levem a construção de uma leitura dos acontecimentos que valorize o processo contínuo de produção.Isto porque as imagens, uma vez sendo suporte de relações sociais, não são apenas efeitos, ou sintomas, mas a própria visualidade como princípio cognitivo de caráter indefectivelmente histórico e teológico.

Longe de ser narrar curiosidades e mera propagação da arte, o uso das imagens na Teologia busca articular os saberes das especificidades do tema, com a crítica de toda e qualquer fonte que se serve as pesquisas.A partir do foco aproximado das experiências e vivências cotidianas o uso das imagens e da iconografia no campo da Teologia amplia as possibilidades de se compreender os fenômenos humanos em relação a sagrado e à sua religiosidade, a partir de conceitos revistos e de reformulações dos postulados teóricos. Interessa, redescobrir as imagens, notadamente aquelas de cunho religioso, quais objetos densos de análise, uma vez que deslumbram-se em sentidos e significados. Assim, no ofício de lidar com as imagens, os historiadores e teólogos podem tirar delas sentidos novos, graças à hermenêutica que o faz intérprete das sensibilidades visuais.

Verifica-se, então, que o uso das imagens na composição de narrativas teológicas encerra-se dentro de um contexto da historicidade visual, antropológica, filosófica e cultural. Uma vez que as imagens estão sujeitas à polissemia dos sentidos, é preciso que se ultrapasse aquilo que esteja aparentemente representado na própria figura e se atente para os usos e funções da imagem num contexto plural de conhecimentos. Importante notar que a utilização da imagem no 
construto de um saber teológico não se constitui em oposição às formas narrativas da escrita da Teologia; é um maneira outra e colaborativa de se teologizar.

Assim, na perspectiva do estudo da Imagem, parece interessar à Teologia a interpretação da ação de Deus na História humana à luz dos teóricos e metodologia novas. Trata-se então de uma hermenêutica crítica sobre o uso das imagens na narrativa teológica dentro de um contexto acadêmico e multidisciplinar explicável. É necessário então debater a utilização pictórica na Teologia dentro de uma lógica e saber específico, sem deixar de se perder pelos deslumbramentos de raciocínios confusos e invasivos.

Além desta conformidade, torna-se fundamental lembrar que, ainda que se utilize de autores que tratam em suas pesquisas da análise das imagens, as teorias e métodos usados para compor um saber teológico devem estar atentos à missão e natureza da Teologia como ciência acadêmica. ${ }^{16}$ Porque não se trata de substituir um conhecimento pelo outro, mas se servir, quando possível, de uma abordagem teórico-metodológica. Esta contribuição monstra que também a ciência teológica está em contínua reconstrução e não prescinde da colaboração e abertura para novos confrontos teóricos.

Logo, a interdisciplinaridade faz com que a Imagem seja percebida em suas várias leituras e apreensões, até porque os recentes pesquisadores da História e Teologia tratam dos assuntos do uso das imagens, levantando problemáticas ancoradas em métodos e aportes conceituais compartilhados e comuns. Desta forma, as crenças, os dogmas, os documentos eclesiásticos, os saberes escritos também deixam de ser observados somente pelas lentes do pesquisador comprometido com determinado olhar epistemológico, levando-o a um exercício interpretativo diferenciado.

16 PAIVA, Eduardo França. História e Imagens. Belo Horizonte: Autêntica, 2002. 


\section{Bibliografia:}

AGOSTINHO. Confissões. Lisboa: Apostolado da Imprensa, 1990.

BERGSON, Henri. Matéria e Memória: Ensaio sobre a relação do corpo com o espírito. São Paulo: Martins Fontes, 1999.

BURUCÚA, José Emilio (Org.). Historia de las imágenes e historia de las ideas. La escuela de Aby Warburg. Buenos Aires: Centro Editor de América Latina, 1992.

CERTEAU, Michel de. A invenção do cotidiano. Artes de fazer. 13 ed. Petrópolis: Editora Vozes, 2007

CHENU, Bruno. Teologie cristiane dei terzi mondi. Roma: Queriniana, 1988.

DI FALC, Jean-Michel; RADCLIFFE, Timothy; RICCARDI, Andrea. Le Livre noir de la condition des chrétiens dans le monde. Paris: XO Editions, 2014.

FABRIS, A. Redefinindo o conceito de imagem. Revista Brasileira de História. São Paulo, v.18, n.35, p. 217-224, 1998.

FILORAMO, Giovanni; BETTIOLO, Paolo. Il Dio mortale. Teologie politiche tra antico e contemporaneo. Brescia: Morcelliana, 2012.

KNAUSS, Paulo (Org.) ; Calainho, Daniela Buono (Org.) . Usos do Passado - XII Encontro Regional de História. Rio de Janeiro: Anpuh-Rio, 2006.

KNITTER, Paul F. Introduzione alle Teologie delle Religioni. Roma: Queriniana, 2012.

LE GOFF, Jacques. História e Memória. Campinas, SP: UNICAMP, 2003.

LEITE, Miriam Lifchitz Moreira. Texto visual e texto verbal. Revista Catarinense de História, n. 5, p. 67-85.

LEVALOIS, Christophe. Prendre soin de l'autre. Une vision chrétienne de la communication.Paris: CERF, 2012.

PAIVA, Eduardo França. História e Imagens. Belo Horizonte: Autentica, 2002

SANTOS, Hugo N. (Org.). Dimensiones del Cuidado y Asesoramiento Pastoral. Buenos Aires: Ediciones Kairós, 2006.

Recebido em: 27/06/2015

Aprovado em: 16/09/2015 